\title{
Monitoring during mechanical ventilation
}

\author{
DEAN HESS PhD RRT \\ Harvard Medical School and Massachusetts General Hospital, Boston, Massachusetts, USA
}

\section{HESS. Monitoring during mechanical ventilation. Can Respir J 1996;3(6):386-393.}

Monitoring is a continuous, or nearly continuous, evaluation of the physiological function of a patient in real time to guide management decisions, including when to make therapeutic interventions and assessment of those interventions. Pulse oximeters pass two wavelengths of light through a pulsating vascular bed and determine oxygen saturation. The accuracy of pulse oximetry is about $\pm 4 \%$. Capnography measures carbon dioxide at the airway and displays a waveform called the capnogram. End-tidal $\mathrm{PCO}_{2}$ represents alveolar $\mathrm{PCO}_{2}$ and is determined by the ventilation-perfusion quotient. Use of end-tidal $\mathrm{PCO}_{2}$ as an indication of arterial $P \mathrm{PO}_{2}$ is often deceiving and incorrect in critically ill patients. Because there is normally very little carbon dioxide in the stomach, a useful application of capnography is the detection of esophageal intubation. Intraarterial blood gas systems are available, but the clinical impact and cost effectiveness of these is unclear. Mixed venous oxygenation $\left(P \overline{\mathrm{v}} \mathrm{O}_{2}\right.$ or $\left.S \overline{\mathrm{v}} \mathrm{O}_{2}\right)$ is a global indicator of tissue oxygenation and is affected by arterial oxygen content, oxygen consumption and cardiac output. Indirect calorimetry is the calculation of energy expenditure and respiratory quotient by the measurement of oxygen consumption and carbon dioxide production. A variety of mechanics can be determined in mechanically ventilated patients including resistance, compliance, auto-peak endexpiratory pressure (PEEP) and work of breathing. The static pressure-volume curve can be used to identify lower and upper infection points, which can be used to determine the appropriate PEEP setting and to avoid alveolar overdistension. Although some forms of monitoring have become a standard of care during mechanical ventilation (eg, pulse oximetry), there is little evidence that use of any monitor affects patient outcome.

Key Words: Capnography, Indirect calorimetry, Lung mechanics, Mixed venous oximetry, Monitoring, Point-of-care testing, Pulse oximetry

\section{Monitorage pendant la ventilation mécanique}

RÉSUMÉ : Le monitorage est une évaluation continue ou quasi continue de la fonction physiologique d'un patient, en temps réel, visant à guider la prise en charge, y compris le choix du moment approprié pour pratiquer des interventions thérapeutiques ainsi que leur évaluation. Les oxymètres digitaux font passer deux longueurs d'onde de lumière à travers un lit vasculaire pulsatile et déterminent la saturation en oxygène. L'exactitude de l'oxymétrie digitale est d'environ $\pm 4 \%$. La capnographie mesure le débit de gaz carbonique excrété à la bouche et affiche une courbe hyperbolique appelée capnogramme. $\mathrm{La} \mathrm{PCO}_{2}$ de fin d'expiration représente la $P_{2} \mathrm{O}_{2}$ alvéolaire, et c'est le rapport ventilation-perfusion qui la définit. L'utilisation de la $\mathrm{PCO}_{2}$ en fin d'expiration comme indicateur de la $\mathrm{PCO}_{2}$ artérielle est souvent trompeuse et incorrecte chez les patients gravement malades. Parce qu'il y a normalement très peu de gaz carbonique dans l'estomac, une application utile de la capnographie est la détection d'une intubation oesophagienne. Les systèmes intra-artériels de gaz du sang sont disponibles, mais leur impact clinique et leur rentabilité ne sont pas établis. L'oxygénation dans le sang veineux mêlé $\left(\mathrm{PVO}_{2}\right.$ ou $\mathrm{SVO}_{2}$ ) est un indicateur global de l'oxygénation des tissus qui est affecté par le contenu d'oxygène artériel, la consommation d'oxygène et le débit cardiaque La calorimétrie indirecte est le calcul de la dépense d'énergie et du quotient respiratoire par la mesure de la consommation d'oxygène et de la production de gaz carbonique. Plusieurs paramètres de la mécanique pulmonaire peuvent être calculés chez les patients ventilés mécaniquement y compris la résistance, la compliance, l'auto-pression expiratoire positive (PEEP) et le travail ventilatoire. La courbe pression-volume statique peut servir à identifier les sites d'infection dans les parties inférieures et supérieures, ce qui permet de déterminer le niveau de PEEP approprié et d'éviter la surdistension alvéolaire. Bien que certains types de monitorage fassent maintenant partie de la routine pendant la ventilation mécanique (par exemple, l'oxymétrie digitale), leur influence bénéfique sur l'état de santé des patients reste à démontrer.

Correspondence and reprints: Dr Dean Hess, Respiratory Care Ellison 401, Massachusetts General Hospital, Boston, MA 02114, USA. Telephone 617-724-4480, fax 617-724-4495, e-mail hessd@a1.mgh.harvard.edu 
$\mathrm{M}$ onitoring is a continuous, or nearly continuous, evaluation of the physiological function of a patient in real time to guide management decisions, including when to make therapeutic interventions and assessment of those interventions. Both invasive and noninvasive monitoring are commonly used with mechanically ventilated patients to assess oxygenation, ventilation, nutritional status and lung mechanics. Some forms of monitoring (eg, pulse oximetry) have become a standard of care during mechanical ventilation. Despite extensive monitoring of these patients, there is little evidence that such practice affects patient outcome. This paper provides a brief overview of monitoring during mechanical ventilation.

\section{PULSE OXIMETRY}

In pulse oximetry two wavelengths of light (usually $660 \mathrm{~nm}$ and $940 \mathrm{~nm}$ ) pass through a pulsating vascular bed, and oxygen saturation $\left(\mathrm{SpO}_{2}\right)$ is derived from the ratio of the amplitudes of the plethysmographic waveforms. Because pulse oximeters evaluate each arterial pulse, many display heart rate as well as $\mathrm{SpO}_{2}$. The saturation reading should be questioned if the oximeter heart rate differs considerably from the actual heart rate or if the signal quality is poor. However, good agreement between the pulse oximeter heart rate and the actual heart rate does not guarantee a correct $\mathrm{SpO}_{2}$ reading.

At saturations greater than $70 \%$, the accuracy of pulse oximetry is about $\pm 4 \%$ to $5 \%$. To appreciate the implications of these accuracy limits, one must consider the oxyhemoglobin dissociation curve. If the pulse oximeter displays $\mathrm{SpO}_{2}$ of $95 \%$, the true saturation could be as low as $90 \%$ or as high as $100 \%$. If the true saturation is $90 \%$, the $\mathrm{PO}_{2}$ is about $60 \mathrm{mmHg}$, whereas the $\mathrm{PO}_{2}$ might be very high $(150 \mathrm{mmHg}$ or greater) if the true saturation is $100 \%$. Below $70 \%$, the accuracy of pulse oximetry is worse, but the clinical importance of this is questionable. Due to the variable and often unknown relationship between $\mathrm{SO}_{2}$ and $\mathrm{PO}_{2}$, one should predict arterial $P_{2}\left(\mathrm{PaO}_{2}\right)$ from $\mathrm{SpO}_{2}$ with extreme caution. Manufacturer-derived calibration curves vary from manufacturer to manufacturer and can vary among pulse oximeters of a given manufacturer. For that reason, the same pulse oximeter and probe should be used for each $\mathrm{SpO}_{2}$ determination on a given patient. Spot checks of $\mathrm{SpO}_{2}$, in which the relationship between $\mathrm{SpO}_{2}$ and $\mathrm{SaO}_{2}$ is unknown for a specific patient, should be interpreted cautiously.

There are a number of performance limitations of pulse oximetry that should be understood by all clinicians who use these devices. Motion of the probe and high intensity ambient light can produce inaccurate readings. Motion artefact can be lessened by attaching the probe to an alternate site (such as the ear or toe rather than the finger), and interference by light can be minimized by wrapping the probe with a light barrier. Both carboxyhemoglobin and methemoglobin produce significant inaccuracy, and pulse oximetry should not be used when elevated levels of these are present. Vascular dyes also affect the accuracy of pulse oximetry, with methylene blue producing the greatest effect. Because pulse oximeters re-

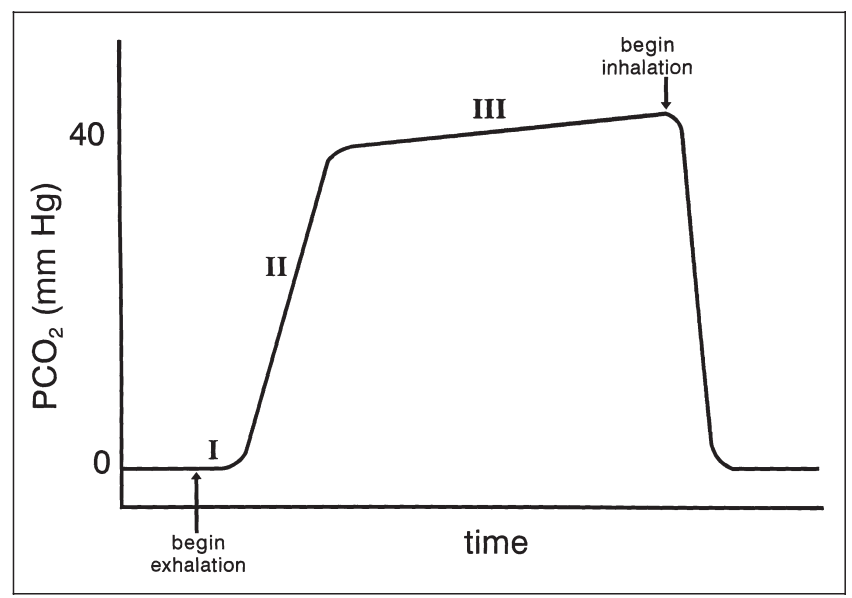

Figure 1) Normal capnogram. I Anatomic dead space; II Mixture of anatomic dead space and alveolar gas; III Alveolar plateau

quire a pulsating vascular bed, they are unreliable with low peripheral perfusion. Nail polish can affect accuracy and it should be removed before pulse oximetry is used. The accuracy and performance of pulse oximetry may also be affected by deeply pigmented skin. The accuracy of pulse oximetry is not affected by hyperbilirubinemia or fetal hemoglobin. Although pulse oximetry is generally considered safe, burns from defective probes and pressure necrosis may occur during monitoring by pulse oximetry.

Pulse oximetry provides little indication of ventilation or acid-base status. Clinically important changes in $\mathrm{pH}$ and/or arterial $\mathrm{PCO}_{2}\left(\mathrm{PaCO}_{2}\right)$ can occur with little change in $\mathrm{SpO}_{2}$. This is particularly true when $\mathrm{SpO}_{2}$ is greater than $95 \%-$ often the case with mechanically ventilated patients. It is important to recognize that pulse oximetry is of limited value during ventilator weaning. Desaturation occurs relatively late in the course of a weaning failure. Because pulse oximetry also does not evaluate tissue oxygen delivery, a patient can have significant tissue hypoxia in spite of an adequate $\mathrm{SpO}_{2}$.

Pulse oximetry is indicated in unstable patients likely to desaturate, in patients receiving a therapeutic intervention that is likely to produce hypoxemia (such as bronchoscopy) and in patients having interventions likely to produce changes in arterial oxygenation (such as changes in fraction of inspired oxygen $\left[\mathrm{FiO}_{2}\right]$ or positive end-expiratory pressure [PEEP]). For the titration of $\mathrm{FiO}_{2}, \mathrm{SpO}_{2}$ of $92 \%$ or greater is reliable in predicting a satisfactory level of oxygenation $\left(\mathrm{PaO}_{2}\right.$ of $60 \mathrm{mmHg}$ or greater) in most adult mechanically ventilated patients. Although pulse oximetry may decrease the number of blood gases required during the titration of $\mathrm{FiO}_{2}$ or PEEP, it does not eliminate the need for periodic blood gases.

\section{CAPNOGRAPHY}

Capnography is the measurement of carbon dioxide at the airway and display of a waveform called the capnogram. Most bedside capnographs use infrared absorption at $4.26 \mu \mathrm{m}$ to measure carbon dioxide. The measurement chamber is placed at the airway with a mainstream capnograph or 


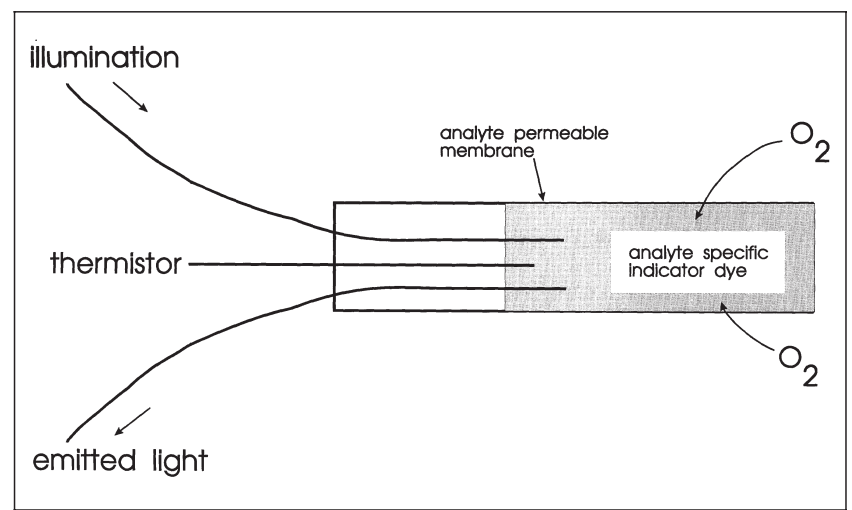

Figure 2) Schematic illustration of optode

gas is aspirated to the measurement chamber inside the capnograph with the sidestream device. There are advantages and disadvantages of each design and neither is clearly superior. There are numerous technical problems related to the use of capnography, including the need for periodic calibration and interference from gases such as nitrous oxide. Water is an important problem because it occludes sample lines in the sidestream capnograph and condenses on the cell of mainstream devices. Manufacturers use a number of features to overcome these problems including water traps, purging of the sample line, construction of the sample line with water vapour-permeable nafion and heating of the mainstream cell.

A schematized capnogram from a normal patient is illustrated in Figure 1. During inspiration, $\mathrm{PCO}_{2}$ is zero. At the beginning of expiration, $\mathrm{PCO}_{2}$ remains zero as gas from anatomic dead space leaves the airway (phase I). $\mathrm{PCO}_{2}$ then sharply rises as alveolar gas mixes with dead space gas (phase II). During most of expiration, the curve levels and forms a plateau (phase III). This represents gas from alveoli and is called the alveolar plateau. $\mathrm{PCO}_{2}$ at the end of the alveolar plateau is called end-tidal $\mathrm{PCO}_{2}\left(\mathrm{PetCO}_{2}\right)$. The shape of the capnogram is abnormal in patients with abnormal lung function.

$P_{\text {etCO }}$ presumably represents alveolar $P_{2} \mathrm{CO}_{2}\left(\mathrm{PACO}_{2}\right)$. $\mathrm{PACO}_{2}$ is determined by the ventilation-perfusion ratio $(\dot{\mathrm{V}} / \dot{\mathrm{Q}})$. With a normal $\dot{\mathrm{V}} / \dot{\mathrm{Q}}, P \mathrm{ACO}_{2}$ approximates $P \mathrm{aCO}_{2}$. If $\dot{\mathrm{V}} / \mathrm{Q}$ decreases, $P \mathrm{ACO}_{2}$ rises towards mixed venous $P \mathrm{CO}_{2}\left(P \overline{\mathrm{v}} \mathrm{CO}_{2}\right)$. With a high $\dot{\mathrm{V}} / \mathrm{Q}$ (ie, dead space), $P \mathrm{ACO}_{2}$

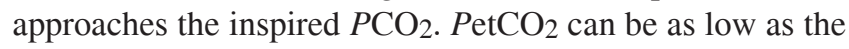
inspired $\mathrm{PCO}_{2}$ (zero) or as high as the $P \overline{\mathrm{v}} \mathrm{CO}_{2}$. An increase or decrease in $\mathrm{PetCO}_{2}$ can be the result of changes in carbon dioxide production (ie, metabolism), carbon dioxide delivery to the lungs (ie, circulation) or alveolar ventilation. However, because of homeostasis, compensatory changes may occur so that $P$ etCO 2 does not change. In practice, $P$ etCO 2 is a nonspecific indicator of cardiopulmonary homeostasis and usually does not indicate a specific problem or abnormality.

The gradient between $\mathrm{PaCO}_{2}$ and $\mathrm{PetCO}_{2}\left[\mathrm{P}(\mathrm{a}\right.$-et $\left.) \mathrm{CO}_{2}\right]$ is normally small (less than $5 \mathrm{mmHg}$ ). There is considerable intra- and interpatient variability in the relationship between $\mathrm{PaCO}_{2}$ and $P$ etCO $2 . P($ a-et $) \mathrm{CO}_{2}$ is often too variable to allow precise prediction of $\mathrm{PaCO}_{2}$ from $P \mathrm{etCO}_{2} . \mathrm{PetCO}_{2}$ as a reflection of $\mathrm{PaCO}_{2}$ is useful only in mechanically ventilated patients who have relatively normal lung function, such as iatrogenic hyperventilation in head-injured patients. $\mathrm{PetCO}_{2}$ is not useful as a predictor of $\mathrm{PaCO}_{2}$ during weaning from mechanical ventilation. Use of $\mathrm{PetCO}_{2}$ as a predictor of $\mathrm{PaCO}_{2}$ is often deceiving and incorrect, and should not be used for this purpose in adult mechanically ventilated patients.

A useful application of capnography is the detection of esophageal intubation. Because there is normally very little carbon dioxide in the stomach, intubation of the esophagus and ventilation of the stomach result in a near-zero $\mathrm{PetCO}_{2}$. A potential problem with the use of capnography to confirm endotracheal intubation occurs during cardiac arrest, with false negative results occurring because of very low $\mathrm{PetCO}_{2}$ values related to decreased pulmonary bloodflow. Relatively inexpensive disposable devices that produce a colour change in the presence of expired carbon dioxide are available to detect esophageal intubation. During resuscitation, changes in pulmonary bloodflow are reflected by changes in $\mathrm{PetCO}_{2}$. However, the use of $\mathrm{PetCO}_{2}$ as a real-time objective indicator of bloodflow during resuscitation is not practical.

Although capnography has become a standard of care in the operating room, its use in the critical care unit cannot be enthusiastically supported. $P \mathrm{etCO}_{2}$ is often an imprecise predictor of $P \mathrm{aCO}_{2}$, particularly in patients with lung disease precisely those in whom its use might be most desirable. Although the use of capnography has been advocated as a backup ventilator disconnect alarm, there is no evidence that it is any better than the alarms currently available on ventilators.

\section{POINT-OF-CARE TESTING AND INTRA-ARTERIAL BLOOD GAS MONITORING}

Point-of-care testing moves the process of blood gas analysis from the laboratory to the bedside. Hand-held portable analyzers are now available to measure blood gases and $\mathrm{pH}$. These devices typically use a disposable cartridge that contains calibration solution, a sample handling system, a waste chamber and miniaturized sensors. In comparison with traditional electrodes, these sensors are less sensitive to drift and require less frequent calibration. The role of point-ofcare blood gas analysis is unclear. The quality and cost effectiveness of this testing remains to be determined.

Although some intra-arterial blood gas systems use a Clark polarographic electrode to measure $\mathrm{PO}_{2}$, most intraarterial blood gas monitoring systems use an optode to measure $P_{2}, P_{2} \mathrm{O}_{2}$ and $\mathrm{pH}$. The optode consists of a miniaturized probe containing a fluorescent dye (Figure 2). The dye changes fluorescence as the $\mathrm{PO}_{2}, \mathrm{PCO}_{2}$ and $\mathrm{pH}$ change $(\mathrm{pH}$ and $P_{2} \mathrm{O}_{2}$ augment fluorescence and $P_{2}$ quenches fluorescence). An optical fibre leads from the probe to a photosensor, which quantifies the amount of light emitted from the dye. There are two clinical approaches to intra-arterial blood gas monitoring. One approach passes the probe through an arterial line, which allows continuous monitoring of blood gases. With the second approach, the probe is attached to the 


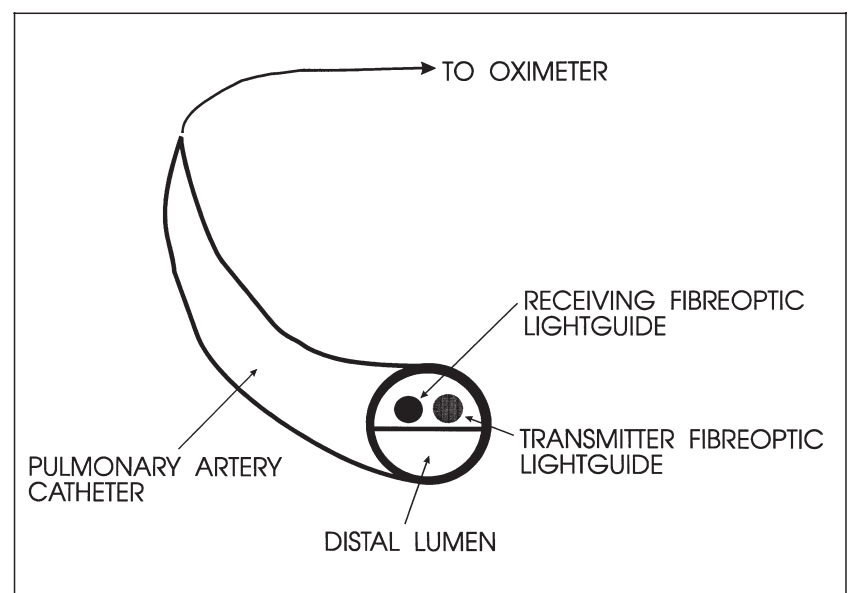

Figure 3) Schematic illustration of pulmonary artery catheter designed to measure mixed venous oxygen saturation

proximal arterial catheter; this system does not allow continuous blood gas monitoring, but does allow frequent ondemand blood gas analysis with no blood loss from the patient. The clinical impact and cost effectiveness of these systems are unclear. The accuracy of these systems also remains problematic. Although bias is low compared with that in traditional blood gas analysis, the precision may be unacceptable. Occasional marked differences between the intra-arterial blood gas system and traditional blood gases is problematic; the intra-arterial milieu may preclude reliable function of these devices.

\section{MIXED VENOUS OXYGENATION}

To assess mixed venous $P_{2}\left(P \overline{\mathrm{v}} \mathrm{O}_{2}\right)$, blood is obtained from the distal port of the pulmonary artery catheter. Normal $P \overline{\mathrm{v}} \mathrm{O}_{2}$ is $40 \mathrm{mmHg}$ and is considered to be a global indication of the level of tissue oxygenation. However, it has also been demonstrated that normal or supranormal values of $P \overline{\mathrm{v}} \mathrm{O}_{2}$ can coexist with severe tissue hypoxia caused by arterial admixture, septicemia, hemorrhagic shock, congestive heart failure and febrile states. Further, $P \overline{\mathrm{v}} \mathrm{O}_{2}$ reveals little about the oxygenation status of individual tissue beds. Factors affecting $P \overline{\mathrm{v}} \mathrm{O}_{2}$ can be illustrated from the Fick equation:

$$
\dot{\mathrm{Q}}=\frac{\dot{\mathrm{V}} \mathrm{O}_{2}}{\left(\mathrm{CaO}_{2}-\mathrm{C}_{\mathrm{V}} \mathrm{O}_{2}\right)}
$$

where $\dot{\mathrm{Q}}$ is perfusion, $\dot{\mathrm{VO}}_{2}$ is oxygen consumption and $\mathrm{CaO}_{2}-\mathrm{C} \overline{\mathrm{v}} \mathrm{O}_{2}$ is the arteriovenous difference in blood oxygen concentration. The Fick equation can be rearranged to solve for $\mathrm{C} \bar{v} \mathrm{O}_{2}$ :

$$
\mathrm{C}_{\mathrm{v}} \mathrm{O}_{2}=\mathrm{CaO}_{2}-\frac{\dot{\mathrm{V}} \mathrm{O}_{2}}{\dot{\mathrm{Q}}}
$$

$\mathrm{C} \overline{\mathrm{v}} \mathrm{O}_{2}$ (and its components $P \overline{\mathrm{v}} \mathrm{O}_{2}$ and mixed venous oxygen saturation $\left[S \bar{v} \mathrm{O}_{2}\right]$ ) is decreased with decreases in $\mathrm{CaO}_{2}$ (ie, $\mathrm{PaO}_{2}, \mathrm{SaO}_{2}$ or hemoglobin), decreases in $\mathrm{Q}$ or increases in $\dot{\mathrm{V}} \mathrm{O}_{2}$. Note that an increase in $\dot{\mathrm{V}} \mathrm{O}_{2}$ with a proportional increase in $\dot{Q}$ does not affect $\mathrm{C} \overline{\mathrm{v}} \mathrm{O}_{2}$. Also note that breathing $100 \%$ oxygen by persons with normal lung function does not

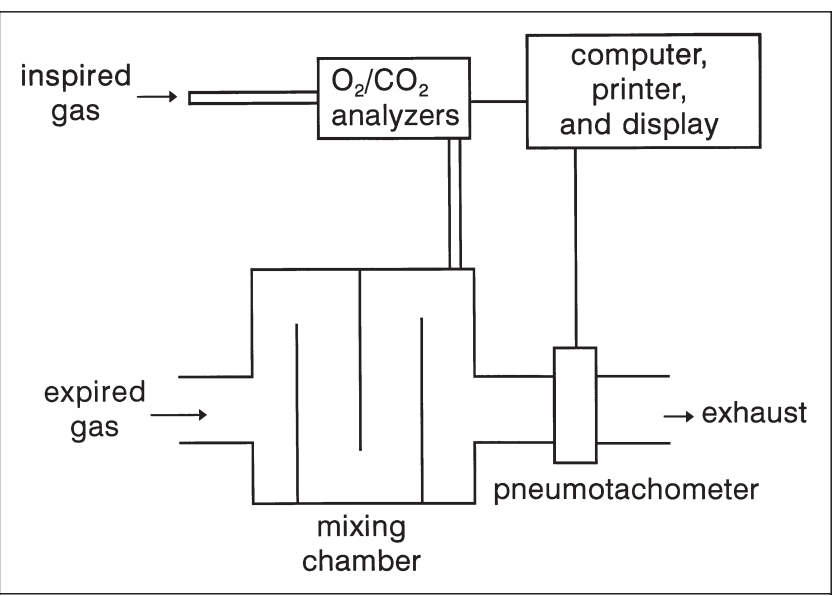

Figure 4) Schematic illustration of open circuit calorimeter

affect $\mathrm{C} \overline{\mathrm{v}} \mathrm{O}_{2}$ because increasing $\mathrm{PaO}_{2}$ affects $\mathrm{CaO}_{2}$ very little (ie, oxygen is very insoluble in blood and hemoglobin is nearly $100 \%$ saturated when breathing room air). In patients with abnormal lung function (eg, shunt), a decrease in $P \overline{\mathrm{v}} \mathrm{O}_{2}$ may produce a decrease in $\mathrm{PaO}_{2}$.

Venous oximetry monitors $S \overline{\mathrm{v}} \mathrm{O}_{2}$ using a system incorporated into the pulmonary artery catheter (Figure 3 ). Light is reflected off red blood cells near the pulmonary artery catheter, and $S \overline{\mathrm{v}} \mathrm{O}_{2}$ is determined as the ratio of transmitted to reflected light. Several commercial systems are available and differ in the number of reference wavelengths and detecting filaments. The clinical benefit of monitoring venous oximetry is unclear. This monitor is often not clinically useful due to imprecision in the measurement system and the nonspecific nature of $S \bar{v} \mathrm{O}_{2}$.

\section{INDIRECT CALORIMETRY}

Indirect calorimetry is the calculation of energy expenditure by the measurement of $\dot{\mathrm{V}} \mathrm{O}_{2}$ and $\dot{\mathrm{V}} \mathrm{CO}_{2}$, which are converted to energy expenditure (Kcal/day) by the Weir method:

$$
\text { Energy }=\left[\left(\dot{\mathrm{VO}}_{2}\right)(3.941)+\left(\dot{\mathrm{VCO}}_{2}\right)(1.11)\right] \cdot 1440
$$

Indirect calorimetry also allows calculation of the respiratory quotient. Indirect calorimeters can use an open circuit method, a closed circuit method or a breath-by-breath method. Indirect calorimetry may be indicated for patients who are malnourished, who are difficult to wean from mechanical ventilation or who have numerous nutritional stress factors.

The open circuit calorimeter measures the concentrations and volumes of inspired and expired gases to determine $\dot{\mathrm{V}}_{2}$ and $\dot{\mathrm{V} C O}$. The principal components of an open circuit calorimeter (metabolic cart) are the analyzers (oxygen and carbon dioxide), a volume measuring device and a mixing chamber (Figure 4). The analyzers must be capable of measuring small changes in gas concentrations, and the volume monitor must be capable of accurately measuring volumes. 
Exhaled gas from the patient is directed into a mixing chamber. At the end of the mixing chamber, a vacuum pump aspirates a small sample of gas for measurement of oxygen and carbon dioxide. The entire volume of gas then exits through a volume monitor. The analyzer periodically measures the inspired oxygen concentration. A microprocessor performs the necessary calculations. Meticulous attention to detail is required to obtain valid results using an open-circuit indirect calorimeter. The $\mathrm{FiO}_{2}$ must be stable and less than 0.60 , the entire system must be leak-free, and the inspired and expired gases must be completely separated.

The closed circuit calorimeter uses a volumetric spirometer, a mixing chamber, a carbon dioxide analyzer and a carbon dioxide absorber. The spirometer is filled with a known volume of oxygen. As the patient rebreathes, oxygen is consumed and carbon dioxide is produced. Carbon dioxide is removed from the system by a carbon dioxide absorber. Expired gas from the patient is analyzed for the fractional concentration of carbon dioxide in expired gas $\left(\mathrm{F}_{\bar{E}} \mathrm{CO}_{2}\right)$. The volume of the spirometer is monitored to measure tidal volume (VT). The difference between end-expiratory volumes is calculated by a microprocessor to determine $\dot{\mathrm{VO}}_{2}$. If the patient is mechanically ventilated, a bag-in-the-box system is used as a part of the inspiratory limb of the calorimeter. The bellows is pressurized by the ventilator, resulting in ventilation of the patient. Leaks from the closed circuit system result in erroneously high $\dot{\mathrm{V}} \mathrm{O}_{2}$ measurements (uncuffed airway, bronchopleural fistula, sidestream capnograph). Another problem with this technique is related to ventilatory support, where compressible volume is increased and trigger sensitivity is decreased. The major advantage of the closed circuit method over the open circuit method is its ability to make measurements at a high $\mathrm{FiO}_{2}$ (up to 1.0).

The breath-by-breath calorimeter analyzes $\mathrm{FiO}_{2}$, fractional concentration of oxygen in expired gas $\left(\mathrm{F}_{\bar{E}} \mathrm{O}_{2}\right)$, $\mathrm{F} \overline{\mathrm{E}} \mathrm{CO}_{2}$ and VT with each breath. This obviates the need for a mixing chamber. The system uses the same gas analysis and volume measuring devices as the open circuit calorimeter, and these systems generally have the same limitations as open circuit systems.

In patients with a pulmonary artery catheter, $\dot{\mathrm{V}}_{2}$ can be calculated from $\mathrm{CaO}_{2}, \mathrm{CvO}_{2}$ and cardiac output as follows:

$$
\dot{\mathrm{VO}}_{2}=\text { cardiac output } \cdot\left(\mathrm{CaO}_{2}-\mathrm{C}_{\mathrm{v}} \mathrm{O}_{2}\right)
$$

This method can only be used if a thermodilution pulmonary artery catheter is in place.

Continuous $24 \mathrm{~h}$ indirect calorimetry will ideally produce the best estimate of resting energy expenditure (REE). However, $24 \mathrm{~h}$ measurements of $\dot{\mathrm{V}} \mathrm{O}_{2}$ and $\dot{\mathrm{V}} \mathrm{CO}_{2}$ are not practical unless the metabolic monitor is an integral part of the ventilator system (eg, Puritan Bennett 7250, Puritan Bennett). For many critically ill patients, it is impossible to obtain measurements for longer than 15 to 30 mins more than once every several days. It is important, however, to recognize that shorter and less frequent measurements less reliably estimate REE. When performing indirect calorimetry, the patient should be resting, undisturbed, motionless, supine and aware of the surroundings (unless comatose). The patient should either be on continuous nutritional support or fasting for several hours before the measurement. Before indirect calorimetry is performed, there should have been no changes in ventilation for at least 90 mins, no changes that affect $\dot{\mathrm{V}} \mathrm{O}_{2}$ for at least 60 mins (change in fever, motion, etc) and stable hemodynamics for at least $2 \mathrm{~h}$. The validity of measurements should be assessed by direct observation rather than relying on a 'steady state' indicator of the calorimeter.

\section{MECHANICS DURING MECHANICAL VENTILATION}

With volume ventilation, airway pressure increases during inspiration as volume is delivered. The peak inspiratory pressure (PIP) varies directly with resistance, end-inspiratory flow, VT and elastance (ie, inversely with compliance). An end-inspiratory pause of sufficient duration ( 0.5 to $2.0 \mathrm{~s})$ allows equilibration between proximal airway pressure and alveolar pressure. This manoeuvre should be applied on a single breath and removed immediately to prevent development of auto-PEEP. During the end-inspiratory pause, there is no flow and a pressure plateau (Pplat) develops as proximal airway pressure equilibrates with alveolar pressure. The pressure during the inspiratory pause is commonly referred to as plateau pressure and represents peak alveolar pressure. The difference between PIP and the Pplat is due to the resistive properties of the system (eg, pulmonary airways, artificial airway), and the difference between Pplat and total PEEP is due to the elastic properties of the system (ie, lung and chest wall compliance).

During pressure ventilation, PIP and Pplat may be equal. This is due to the flow waveform that occurs during this mode of ventilation. With pressure ventilation, flow decreases during inspiration and is often followed by a period of zero-flow at end-inspiration. During this period of no flow, proximal airway pressure should be equal to peak alveolar pressure. It follows that PIP should be lower during pressure ventilation than during volume ventilation. With volume ventilation, PIP is greater than Pplat due to the presence of end-inspiratory flow. With pressure ventilation, PIP equals Pplat if end-inspiratory flow is zero. With all other factors held constant (eg, VT, lung impedance, PEEP), Pplat is identical for volume and pressure ventilation. Because lung injury is related primarily to peak alveolar pressure (ie, Pplat), the importance of the decrease in PIP that occurs when changing from volume to pressure ventilation is questionable. It is now commonly accepted that Pplat should ideally be maintained below $35 \mathrm{~cm} \mathrm{H}_{2} \mathrm{O}$ in patients with normal chest wall compliance (ie, transpulmonary pressure less than $30 \mathrm{~cm} \mathrm{H}_{2} \mathrm{O}$ ).

An end-expiratory pause can be used to determine autoPEEP. This method is only valid if the patient is not actively breathing and there are no system leaks (eg, circuit leak or bronchopleural fistula). For patients who are actively breathing, an esophageal balloon is needed to determine autoPEEP. During the end-expiratory pause, there is an equilibration between end-expiratory pressure (total PEEP) 


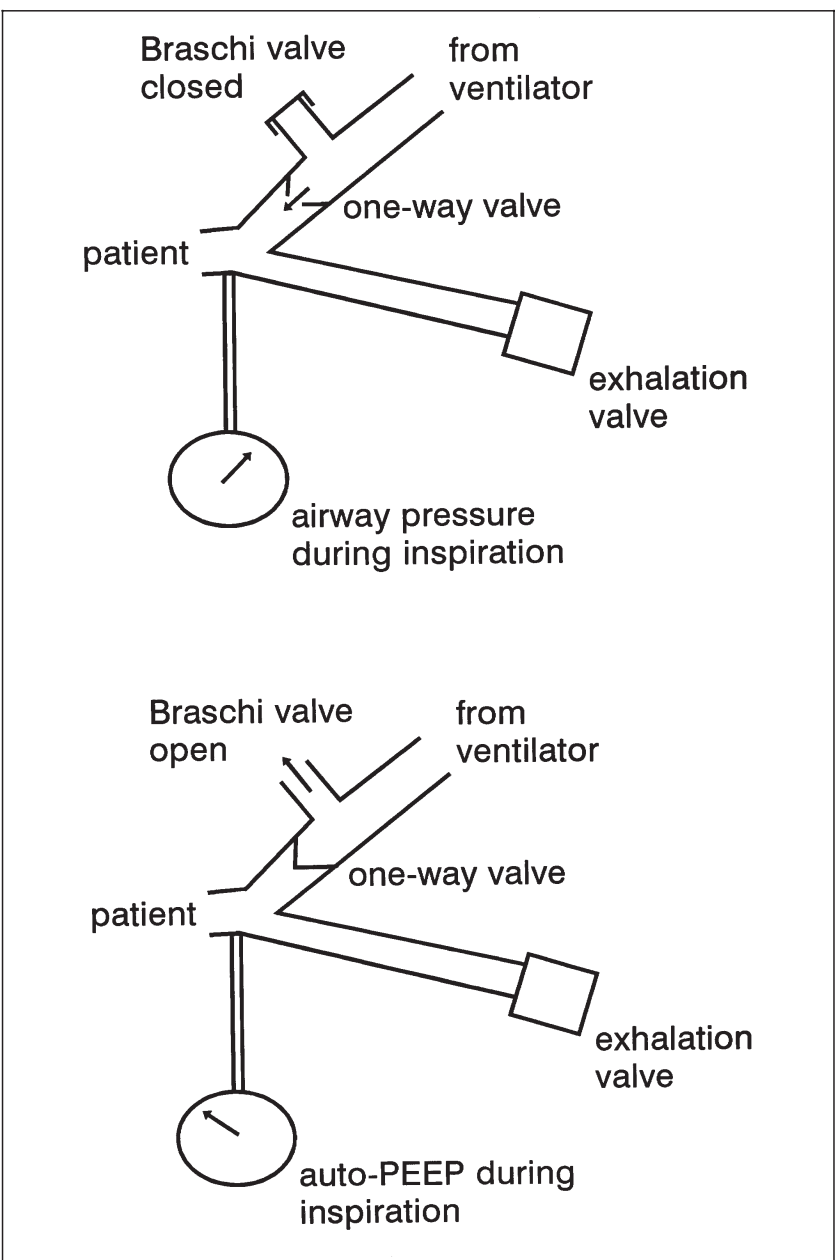

Figure 5) Braschi valve. Top With valve closed, ventilator system operates normally. Bottom With the valve opened during expiration, the next breath from the ventilator is delivered to the atmosphere. During inspiration, the one-way valve of the Braschi valve closes as well as the expiration valve - thus, an end-expiratory hold as long as the inspiratory time is created and pressure measured at the proximal airway is the total alveolar end-expiratory pressure. PEEP Positive end-expiratory pressure

and proximal airway pressure. Auto-PEEP is the difference between set PEEP and total PEEP. An end-expiratory pause can be applied on some ventilators by use of the expiratoryhold control. For ventilators that do not have this control, auto-PEEP can be measured by use of a Braschi valve (Figure 5). Auto-PEEP varies directly with VT, compliance $(C)$ and resistance $(R)$, and inversely with expiratory time:

$$
\text { auto-PEEP }=\frac{\mathrm{VT}}{C\left(\mathrm{e}^{\mathrm{KE} \cdot \mathrm{TE}}-1\right)}
$$

where $\mathrm{KE}=1 /(R \mathrm{E} \cdot C)$, e is the base of the natural logarithm and TE is expiratory time. It is important to detect the presence of auto-PEEP because it can cause hyperinflation, barotrauma and hemodynamic instability. Auto-PEEP also makes triggering more difficult with assisted and spontaneous breathing.

Evaluation of the static pressure-volume (P-V) curve may

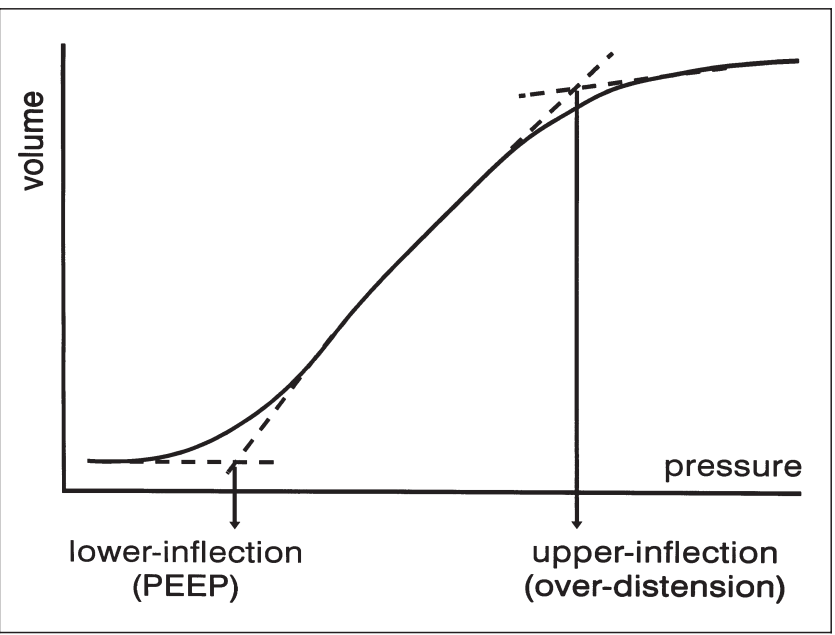

Figure 6) Static pressure-volume curve. Note the lower and upper inflection points. Positive end-expiratory pressure (PEEP) should be set above the lower inflection point and tidal volume should be set below the upper inflection point

\section{TABLE 1}

\section{Equations to calculate pulmonary mechanics during} mechanical ventilation

\section{Mean airway pressure}

Pressure ventilation:

$$
\overline{\mathrm{P}} \mathrm{aw}=(\mathrm{PIP}-\mathrm{PEEP})\left(\frac{\mathrm{Ti}}{\mathrm{T}_{\mathrm{T}}}\right)+\mathrm{PEEP}
$$

Constant-flow volume ventilation:

$$
\overline{\mathrm{P}} \mathrm{aw}=0.5(\mathrm{PIP}-\mathrm{PEEP})\left(\frac{\mathrm{Ti}}{\mathrm{T}_{\mathrm{T}}}\right)+\mathrm{PEEP}
$$

Compliance

$$
C=\frac{\mathrm{VT}}{\text { Pplat }- \text { PEEPtot }}
$$

\section{Resistance:}

Inspiratory resistance:

$$
R \mathrm{I}=\frac{\mathrm{PIP}-\text { Pplat }}{\dot{\mathrm{V}}_{\mathrm{I}}}
$$

Expiratory resistance:

$$
R \mathrm{E}=\frac{\text { Pplat }- \text { PEEPtot }}{\dot{\mathrm{V}} \max }
$$

Work of breathing

$$
\mathrm{W}=\frac{\mathrm{PIP}-(0.5)(\text { Pplat })}{100} \cdot \mathrm{VT}_{\mathrm{T}}
$$

PEEP Positive end-expiratory pressure; PEEPtot Total PEEP; PIP Peak inspiratory pressure; Pplat Pressure plateau; Ti Inspiratory time; TT Total respiratory cycle time; VEmax Peak expiratory flow; $V_{I}$ Inspiratory flow; VT Tidal volume

be useful for patients with acute respiratory distress syndrome (ARDS). In such patients, the P-V curve typically has a sigmoidal shape with an inflection point at low lung volume (lower Pflex) and another inflection point at high lung vol- 
ume (upper Pflex) (Figure 6). PEEP should be set above the lower Pflex to avoid repeated opening and closing of lung units with each respiratory cycle. Likewise, Pplat should be set below the upper Pflex to avoid overdistension injury to the lungs. In other words, the patient should be ventilated on the linear compliant part of the P-V curve. The P-V curve can be constructed for individual patients by changing inspired VT for a few breaths and measuring the resultant Pplat (after which the baseline level of ventilation is re-established). If this procedure is performed for a sufficient number of VTs, the static P-V curve can be constructed. To identify the lower Pflex, PEEP must be removed during these manoeuvres. It must be recognized that the static P-V curve so constructed is different from the dynamic P-V curve displayed on ventilator lung mechanics displays. The dynamic P-V curve only approximates the static P-V curve during constant slow inflation. The dynamic P-V curve is not a valid reflection of lung mechanics with decelerating flow patterns such as those that occur with pressure ventilation.

From measurements of pressure and VT, it is possible to calculate mean airway pressure ( $\overline{\mathrm{P}} \mathrm{aw})$, resistance, compliance and work of breathing (Table 1). Many of the desired and deleterious effects of mechanical ventilation are determined by $\overline{\mathrm{P}}$ aw. Factors affecting $\overline{\mathrm{P}}$ aw are PIP, PEEP, inspi-

\section{BIBLIOGRAPHY}

1. AARC Clinical Practice Guideline. Capnography/capnometry during mechanical ventilation. Respir Care 1995;40:1321-4.

2. AARC Clinical Practice Guideline. Metabolic measurement using indirect calorimetry during mechanical ventilation. Respir Care 1994;39:1170-5.

3. AARC Clinical Practice Guideline. Pulse oximetry. Respir Care 1991;36:1406-9.

4. Bhavani-Shankar K, Kumar AY, Moseley HSL, Ahyee-Hallsworth R. Terminology and the current limitations of time capnography: a brief review. J Clin Monit 1995;11:175-82.

5. Branson RD. The measurement of energy expenditure: instrumentation, practical considerations, and clinical application. Respir Care 1990;35:640-59.

6. Branson RD. Monitoring ventilator function. Crit Care Clin 1995;11:127-43.

7. Bursztein S, Elwyn DH, Askanazi J, Kinney JM. Energy Metabolism, Indirect Calorimetry, and Nutrition. Baltimore: Williams and Wilkins, 1989.

8. Graybeal JM, Russell GB. Capnometry in the surgical ICU: an analysis of the arterial-to-end-tidal carbon dioxide difference. Respir Care 1993;38:923-8.

9. Harrison RA. Monitoring respiratory mechanics. Crit Care Clin 1995;11:151-67.

10. Hess D. Capnometry and capnography: technical aspects, physiologic aspects, and clinical applications. Respir Care 1990;35:557-76.

11. Hess D. Noninvasive monitoring in respiratory care - present, past, and future: an overview. Respir Care 1990;35:482-99.

12. Hess D. Noninvasive respiratory monitoring during ventilatory support. Crit Care Nursing Clin North Am 1991;3:565-74.

13. Hess D, Agarwal NN. Variability of blood gases, pulse oximeter saturation, and end-tidal carbon dioxide pressure in stable, mechanically ventilated patients. J Clin Monit 1992;8:111-5.

14. Hess D, Eitel D. Monitoring during resuscitation. Respir Care 1992;37:739-68.

15. Hess D, Kacmarek RM. Techniques and devices for monitoring oxygenation. Respir Care 1993;38:646-71.

16. Hess DR, Munforff J. Assessment of metabolic and nutritional status. In: Pierson DJ, Kacmarek RM. Foundations of Respiratory Care. New York: Churchill Livingstone, 1992.

17. Hess D, Tabor T. Comparison of six methods to calculate airway resistance during mechanical ventilation. J Clin Monit 1993;9:275-82. ratory:expiratory ratio, respiratory rate and the inspiratory pressure waveform. Typical $\overline{\mathrm{P}}$ aw values for passively ventilated patients are 5 to $10 \mathrm{~cm} \mathrm{H}_{2} \mathrm{O}$ (normal), 20 to $30 \mathrm{~cm} \mathrm{H}_{2} \mathrm{O}$ (ARDS) and 10 to $20 \mathrm{~cm} \mathrm{H}_{2} \mathrm{O}$ (airflow obstruction). The difference between Pplat and total PEEP is determined by the combined compliance of the lung and chest wall. The VT used to calculate compliance should be corrected for the effects of volume compressed in the ventilator circuit, and PEEP should include auto-PEEP. Causes of a decrease in compliance in mechanically ventilated patients include pneumothorax, mainstem intubation, congestive heart failure, ARDS, consolidation, pneumonectomy, pleural effusion, abdominal distension and chest wall deformity. Airway resistance can be calculated from measurements of pressure and flow. Causes of increased resistance during mechanical ventilation include bronchospasm, secretions, small endotracheal tube and mucosa edema. Inspiratory resistance is typically less than expiratory resistance due to the increased diameter of airways during inspiration and the presence of the endotracheal tube. The units for work of breathing are kilogram-meter $(\mathrm{kg}-\mathrm{m})$ or joules $(\mathrm{J}) ; 0.1 \mathrm{~kg}-\mathrm{m}=1.0 \mathrm{~J}$. Normal work of breathing is $0.5 \mathrm{~J} / \mathrm{L}$. Work of breathing increases with an increase in resistance, a decrease in compliance or an increase in VT.

18. Inman KJ, Sibbald WJ, Rutledge FS, Speechley M, Martin CM, Clark BJ. Does implementing pulse oximetry in a critical care unit result in substantial arterial blood gas savings? Chest 1993;104:542-6.

19. Jubran A, Tobin MJ. Reliability of pulse oximetry in titrating supplemental oxygen therapy in ventilator-dependent patients. Chest 1990;97:1420-5.

20. Kacmarek RM, Hess D, Stoller JK. Monitoring in Respiratory Care. Chicago: Mosby-Year Book, 1993.

21. Kelleher JF. Pulse oximetry. J Clin Monit 1989;5:37-62.

22. Larson CP, Vender J, Seiver A. Multisite evaluation of a continuous intraarterial blood gas monitoring system. Anesthesiology 1994;81:543-52.

23. Marini JJ. Lung mechanics determinations at the bedside: instrumentation and clinical measurement. Respir Care 1990;35:669-96.

24. Marini JJ, Crooke PS. A general mathematical model for respiratory mechanics relevant to the clinical setting. Am Rev Respir Dis 1993;147:14-24.

25. Marini JJ, Ravenscraft SA. Mean airway pressure: physiologic determinants and clinical importance - Part 1. Physiologic determinants and measurements. Crit Care Med 1992;20:1461-72.

26. Marini JJ, Ravenscraft SA. Mean airway pressure: physiologic determinants and clinical importance - Part 2. Clinical implications. Crit Care Med 1992;20:1604-16.

27. Marini JJ, Rodriquez RM, Lamb V. Bedside estimation of work of breathing during mechanical ventilation. Chest 1986;89:56-63.

28. Nelson LD. Continuous venous oximetry in surgical patients. Ann Surgery 1986;203:329-33.

29. Primiano FP, Chatburn RL, Lough MD. Mean airway pressure: theoretical considerations. Crit Care Med 1982;10:378-83.

30. Peruzzi WT, Shapiro BA. Blood gas monitors. Respir Care Clin 1995;1:143-56.

31. Roupie E, Dambrosio M, Servillo G, et al. Titration of tidal volume and induced hypercapnia in acute respiratory distress syndrome. Am J Respir Crit Care Med 1995;152:121-8.

32. Schmitz BD, Shapiro BA. Capnography. Respir Care Clin 1995;1:107-17.

33. Severinghaus JW, Kelleher JF. Recent developments in pulse oximetry. Anesthesiology 1992;76:1018-38.

34. Shapiro BA. In-vivo monitoring of arterial blood gases and $\mathrm{pH}$. Respir Care 1992;37:165-9.

35. Sherman MS. A predictive equation for determination of resting energy expenditure in mechanically ventilated patients. Chest 1994;105:544-9. 
36. Siggaard-Anderson O, Fogh-Andersen N, Gøthgen IH, Larsen VH. Oxygen status of arterial and mixed venous blood. Crit Care Med 1995;23:1284-93.

37. Stock MC. Capnography for adults. Crit Care Clin 1995;11:219-32.

38. Smith BL, Vender JS. Point-of-care testing. Respir Care Clin 1995;1:133-41

39. Truwitt JD, Marini JJ. Evaluation of thoracic mechanics in the ventilated patient. Part 1: Primary measurements. J Crit Care 1988;3:133-50.

40. Truwitt JD, Marini JJ. Evaluation of thoracic mechanics in the ventilated patient. Part 2: Applied mechanics. J Crit Care 1988;3:199-213.

41. Wahr JA, Tremper KK. Noninvasive oxygen monitoring techniques. Crit Care Clin 1995;11:199-217.

42. Wahr JA, Tremper KK, Diab M. Pulse oximetry. Respir Care Clin 1995; 1:77-105.

43. Weissman C, Tremper M. Metabolic measurements in the critically ill. Crit Care Clin 1995;11:169-97.

44. Welch JP, DeCesare R, Hess D. Pulse oximetry: instrumentation and clinical applications. Respir Care 1990;35:584-601. 


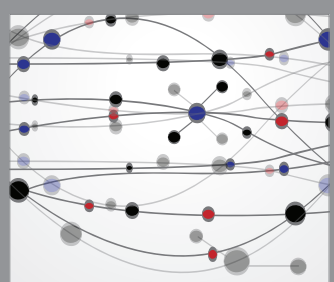

The Scientific World Journal
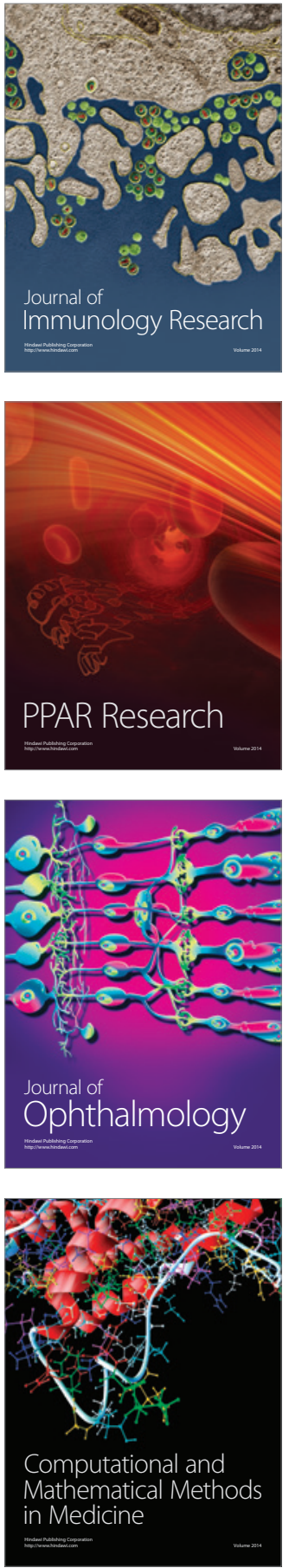

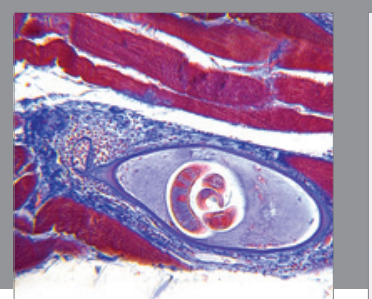

Gastroenterology Research and Practice

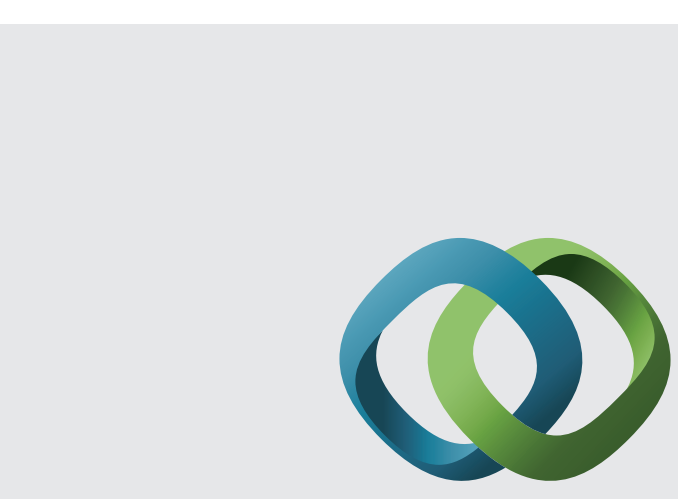

\section{Hindawi}

Submit your manuscripts at

http://www.hindawi.com
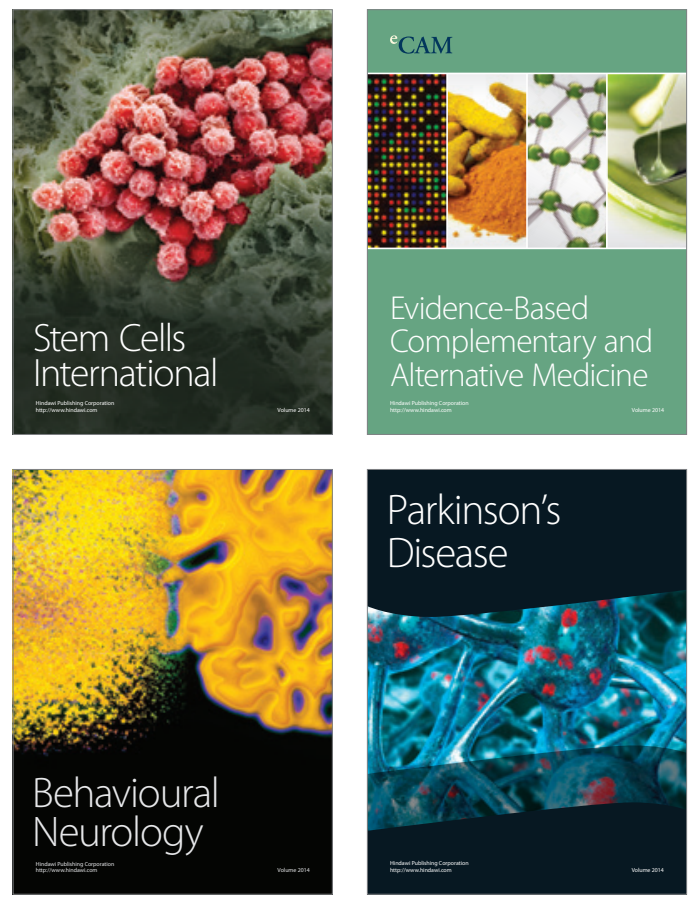
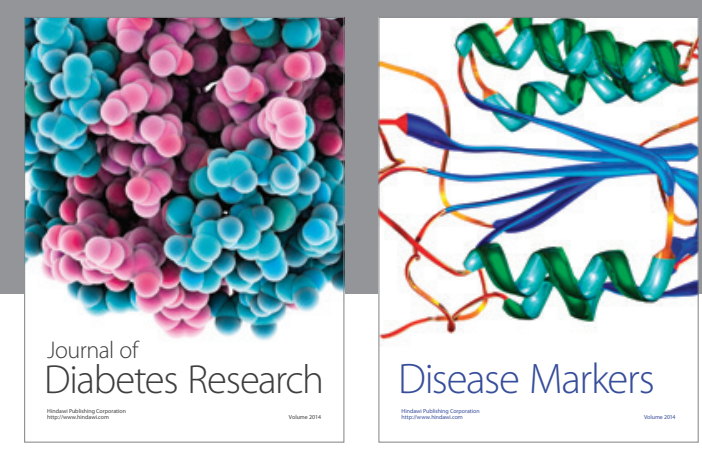

Disease Markers
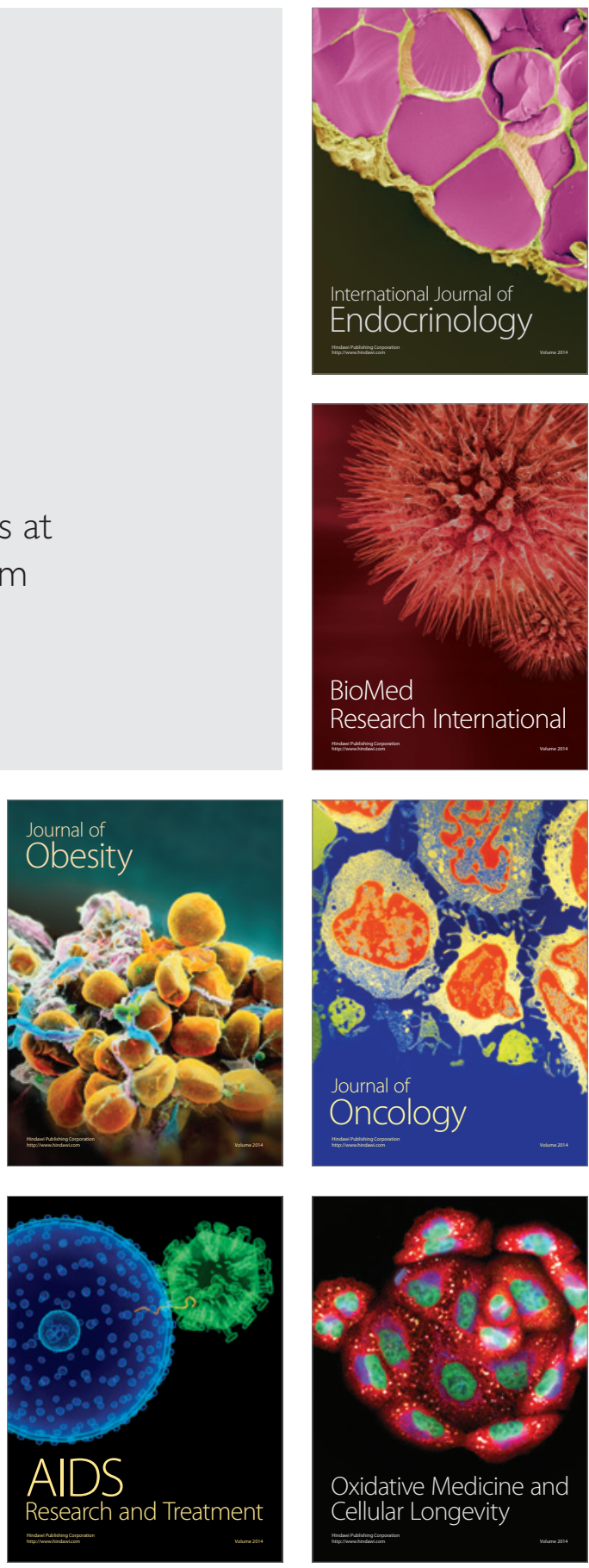